\title{
Estabilidade de silagens de grãos úmidos de milho e milho reidratado
}

\author{
Stability of high moisture corn silage and corn rehydrated
}

\author{
SILVA, Camilla Mendonça ${ }^{1 *}$; AMARAL, Pedro Nelson César do ${ }^{2}$; BAGGIO, Rafael \\ Alan $^{3}$; TUBIN, Jiovani Sergio Bee ${ }^{3}$; CONTE, Renato Augusto ${ }^{3}$; PIVO, João Carlos Dal ${ }^{3}$; \\ KRAHL, Gustavo ${ }^{4}$; ZAMPAR, Aline ${ }^{3}$; PAIANO, Diovani ${ }^{3}$
}

\author{
${ }^{1}$ Universidade Estadual de Mato Grosso do Sul, Programa de Pós-Graduação em Zootecnia, Aquidauana, \\ Mato Grosso do Sul, Brasil. \\ ${ }^{2}$ Universidade Estadual de Mato Grosso do Sul, Curso de Zootecnia, Aquidauana, Mato Grosso do Sul, Brasil. \\ ${ }^{3}$ Universidade do Estado de Santa Catarina, Departamento de Zootecnia, Chapecó, Santa Catarina, Brasil. \\ ${ }^{4}$ Universidade do Oeste de Santa Catarina, Campos Novos, Santa Catarina, Brasil. \\ *Endereço para correspondência: camillamsa@bol.com.br
}

\section{RESUMO}

Este trabalho foi realizado para avaliar as características fermentativas e a estabilidade aeróbica das silagens de grãos úmidos de milho: convencional, doce e reidratado. Foi utilizado um delineamento em esquema fatorial $3 \times 3 \mathrm{com}$ três tipos de milho (Fortuna, doce e reidratado) e três tratamentos de inoculação (sem inoculação; com inoculação bacteriana; inoculação bacteriana mais enzimas). Foram avaliados a estabilidade aeróbica (diferença entre temperatura do bulbo seco e temperatura das silagens) e os valores de $\mathrm{pH}$ com: $0,24,48,72,96,168,192,216,240$ e 296 horas de exposição aeróbica. Adicionalmente, foram testados diferentes modelos matemáticos para estimar os valores médios de $\mathrm{pH}$ pós abertura. Houve interação $(\mathrm{P}<0,05)$ entre os tratamentos de inoculação e tipos de milho para a estabilidade aeróbica e para $\mathrm{pH}$ nas horas 72,168 e 192 após a abertura dos silos. As silagens de milho doce inoculadas apresentaram melhor estabilidade aeróbica quando comparadas com as demais silagens. Para o $\mathrm{pH}$ às 48 horas a silagem de milho doce apresentou os menores valores de $\mathrm{pH}$. $\mathrm{O}$ tratamento inoculação mais enzimas para a silagem de milho reidratado reduziu o $\mathrm{pH} 168$. A equação de Richard (1959) foi a que melhor estimou os valores de $\mathrm{pH}$ para os tipos de inoculação e para o milho reidratado. Para as silagens de milho fortuna e doce o modelo proposto por Morgan et al. (1975) foi o que melhor ajustou os dados.

Palavras-chave: inoculante, milho doce, modelos matemáticos, $\mathrm{pH}$

\section{SUMMARY}

This work was carried out to evaluate the fermentation characteristics and aerobic stability, regarding the conventional high moisture corn grain silage (Fortuna variety), the high moisture sweet corn grain silage and the high moisture rehydrated corn silage. Data were statistically analyzed as a $3 \times 3$ factorial arrangement in a completely randomized design, and the factors were three types of corn (Fortuna, sweet and rehydrated) and three inoculation treatments (without inoculum, bacterial inoculum and bacterial inoculum plus enzymes). The aerobic stability values were assessed, collecting the temperatures from the room dry bulb and from the silage thermometers, and the $\mathrm{pH}$ values, at 0,24 , 48, 72, 96, 168, 192, 216, 240 and 296 hours after aerobic exposition. Additionally, different mathematical models to estimate the mean $\mathrm{pH}$ values after opening were tested. Interactions were observed $(\mathrm{P}<0.05)$ between types of corns 
and inoculants for aerobic stability and $\mathrm{pH}$ at 72 , 168 and 192 hours after opening. Inoculated sweet corn silages presented better aerobic stability after aerobic exposition compared to the other silages. The sweet corn silage presented lowest $\mathrm{pH}$ values at 48 hours after opening. The $\mathrm{pH}$ values at 168 hours of rehydrated corn silage treated with bacterial inoculum plus enzymes was more acid. Richard's Equation (1959) was the best tool for the $\mathrm{pH}$ estimation when either types of inoculants or rehydrated corn silage were considered. On the other hand, the model proposed by Morgan et al. (1975) was the best equation model to fit the data regarding either Fortuna or sweet corn silages.

Keywords: inoculant, sweet corn, mathematical models, $\mathrm{pH}$

\section{INTRODUÇÃO}

A ensilagem de grãos úmidos de milho é uma alternativa no armazenamento de grãos na propriedade rural, esta técnica diminui os custos por quilograma de animal produzido em relação ao milho seco (SILVA et al., 2006). Tradicionalmente, as silagens de grãos de milho são produzidas a partir de variedades pertencentes à espécie Zea mays $\mathrm{L}$.

Entretanto, grãos de milho doce pertencentes ao grupo saccharata, podem ser uma boa opção na produção de silagens de grãos úmidos, visto que, por apresentarem presença de alelos mutantes que bloqueiam a conversão de açúcar em amido, dão ao grão a caraterística de possuir um teor maior de açucares solúveis (ZÁRATE \& VIEIRA, 2003), que podem favorecer as caraterísticas fermentativas em relação aos grãos de milho convencionais. Em função da baixa atividade de amilase pancreática de leitões recém desmamados (MAKKINK et al., 1994), a silagem de milho doce poderia ser uma alternativa na nutrição nesta fase.
As silagens de grão de milho apresentam alta quantidade de ácido lático, o que as tornam mais susceptíveis a deterioração após a abertura (BERNARDES et al., 2012). Supõe-se que o uso de inoculantes no momento da ensilagem possa aumentar a estabilidade aeróbia durante $\mathrm{o}$ fornecimento no comedouro (MENDES et al., 2008). Isto justificaria sua aplicação como uma alternativa para a preservação do material quando exposto ao ar, pois confere vantagens aos produtores. $\mathrm{O}$ fornecimento de silagem deteriorada pode resultar em redução no consumo de matéria seca e redução do desempenho do animal (DOLCI et al., 2011). Silagens de milho inoculadas com bactérias homoláticas e enzimas apresentaram maior estabilidade aeróbia quando comparada as silagens não inoculadas (GIMENES et al., 2006). Apesar dos pontos citados não foi encontrado, no levantamento bibliográfico realizado, trabalhos que avaliassem o uso de diferentes silagens entre as quais foram avaliadas variedades de milho doce e suas respectivas combinações com tratamentos de inoculação.

Diante do exposto, este estudo foi realizado com a finalidade de avaliar a estabilidade aeróbica de silagens de grãos úmidos de milho doce, silagens de grãos úmidos de milho fortuna e silagem de grãos de milho secos reidratados submetidos à inoculação bacteriana e inoculação bacteriana mais enzimas carboidratases.

\section{MATERIAS E MÉTODOS}

Foram utilizados para o estudo o híbrido milho doce Tropical Syngenta $^{\circledR}$, a variedade SCS 154 Fortuna da EPAGRI ${ }^{\circledR}$ e milho comum reidratado. O cultivo destas variedades de milho foi realizada 
na Fazenda Experimental do Centro Educacional do Oeste/UDESC Oeste

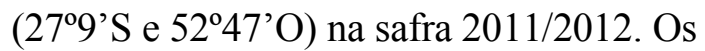
teores de umidade foram monitorados diariamente e o milho foi ensilado quando a umidade atingiu aproximadamente $35 \%$. $\mathrm{O}$ milho seco foi adquirido no comércio. local de Chapecó/SC e reidratado para o mesmo teor de umidade.
Foram determinados os teores de matéria seca (MS), matéria orgânica (MO), proteína bruta $(\mathrm{PB})$, fibra em detergente neutro (FDN) e fibra em detergente ácido (FDA) do material inicial antes da ensilagem (Tabela 1), de acordo com a metodologia proposta por Silva \& Queiroz (2002).

Tabela 1. Composição (com base na matéria seca) inicial e densidade de compactação das silagens de grãos úmidos de milho SCS 154 Fortuna EPAGRI ${ }^{\circledR}$, milho doce Tropical Syngenta ${ }^{\circledR}$ e milho reidratado

\begin{tabular}{lccc}
\hline Itens & Fortuna & Doce & Reidratado \\
\hline Matéria seca, \% & 62,19 & 60,33 & 65,51 \\
Matéria orgânica, \% & 98,74 & 98,10 & 97,49 \\
Proteína bruta, \% & 10,70 & 10,90 & 9,70 \\
Fibra em detergente neutro, \% & 7,59 & 17,34 & 7,59 \\
Fibra em detergente ácido, \% & 1,74 & 4,89 & 1,54 \\
Densidade, $\mathrm{kg} / \mathrm{m}^{3}$ & 1240 & 1160 & Não avaliado \\
\hline
\end{tabular}

Após a colheita o material foi triturado, fracionado em três partes e cada parte recebeu um dos diferentes tratamentos, sem inoculação microbiana (tratamento controle), com inoculação microbiana e com inoculação microbiana mais enzimas carboidratases. O milho seco foi triturado previamente à hidratção. $\mathrm{O}$ inoculante foi adicionado na massa a ser ensilada por aspersão na proporção de 50 gramas do produto, diluído em dois litros de água destilada por tonelada de massa, de acordo com orientações do fabricante. $\mathrm{O}$ inoculante microbiano era constituído por Lactobacillus plantarum, Pediococcus penttosaceous, Pediococcus acidilactici, Lactobacillus rhamnosus, Lactobacillus lactis, Bacillus subtilis e dextrose em uma concentração de $1,667 \times 10^{9} \quad \mathrm{UFC} / \mathrm{g}$. A silagem com inoculante mais complexo enzimático foi elaborado com as cepas e concentração semelhantes, mais as carboidratases.

As variedades fortuna $\mathrm{e}$ doce foram acondicionadas em mini silos, confeccionados em baldes plásticos com capacidade de armazenamento de 20 L, com válvulas tipo "Bunsen" para o escape dos gases produzidos, conforme metodologia preconizada por Jobim et al. (2007). Para o milho reidratado foram utilizados silos experimentais confeccionados em sacos de polietileno fechados a vácuo, com capacidade para dois litros, de acordo com a metodologia sugerida por Hoedtke \& Zeyner (2011). Foram utilizados tipos diferentes de silo visto a facilidade laboratorial de uso dos silos tipo saco e por autores como Neumann et al. (2007), não encontrarem diferenças para o $\mathrm{pH}$ de silagens de planta de milho entre o silo tipo trincheira e silos 
laboratoriais e o trabalho de Rodrigues et al. (2002) no qual não obtiveram diferença entre o $\mathrm{pH}$ de silos do tipo balde e silos do tipo saco. Todos os silos foram adequadamente vedados e armazenados até o período da respectiva abertura que ocorreu no $45^{\circ}$ dia após ensilagem.

Foi utilizado um delineamento inteiramente ao acaso em esquema fatorial $3 \times 3$, três tipos de milho e três tipos de inoculações, com três repetições para os tratamentos do milho SCS 154 Fortuna EPAGRI ${ }^{\circledR}$ e o milho doce Tropical Syngenta ${ }^{\circledR}$ e cinco para o tratamento de milho reidratado, os quais totalizaram 33 unidades experimentais. Imediatamente após a abertura dos silos (45 dias após ensilagem), todo o conteúdo de silagem foi retirado, homogeneizado e acondicionados em baldes plásticos, mantidos em temperatura ambiente, para a avaliação da estabilidade aeróbica.

A análise da estabilidade aeróbica foi realizada com base na diferença entre a temperatura da silagem e a temperatura do bulbo seco (TBS) do ambiente, na qual foi analisado o tempo (horas) necessárias para a temperatura do silo se igualar a TBS, e se elevar em 2,5 e $10^{\circ} \mathrm{C}$ acima da TBS, de acordo com a metodologia sugerida por Kung et al. (2003). Após 24 horas de exposição aeróbica foram realizadas as análises de $\mathrm{pH}$, posteriormente em intervalos de 24 horas até às 296 horas, de acordo com as metodologias preconizadas por Silva \& Queiroz (2002).

Com os valores médios de $\mathrm{pH}$ ao longo dos dias de exposição aeróbica foram elaboradas equações sigmoides conforme a metodologia proposta por Lima \& Silva (2003), em que foram testados os modelos de Gompertz (1825), Richards (1959), Haverkamp \& Parlange (1986) e Morgan et al. (1975), dos quais foi utilizado o modelo que minimizou o erro quadrado entre os valores das variáveis observadas e estimadas. O ajuste das equações dos modelos candidatos foi realizado por meio da ferramenta Solver do Excel no modo evolutionary, visto a complexidade das estimativas.

Os demais dados foram analisados quanto à normalidade e transformados se necessários, foram consideradas nas análises o tipo de milho, tipo de inoculação e as interações entre tipo de milho e inoculações. Foi utilizado para comparação das médias o teste Tukey, adotando-se 5\% como nível de significância e foi utilizado nas análises o software estatístico $\mathrm{SAS}^{\circledR}$.

\section{RESULTADOS E DISCUSSÕES}

Houve interação $(\mathrm{P}<0,05)$ entre os tratamentos de inoculação e tipos de milho para a estabilidade aeróbica das silagens (Tabela 2), o desdobramento das interações (Tabela 3) indicou que para as silagens de milho doce inoculadas houve melhora na estabilidade aeróbica $(\mathrm{P}<0,05)$. Resultados semelhantes foram encontrados por Rabelo et al. (2012), que observaram que a utilização de inoculantes promoveram efeitos positivos para a estabilidade aeróbica de silagens de planta inteira de milho fabricadas em estágio de maturidade avançados.

$\mathrm{O}$ período necessário para elevar a temperatura da massa exposta em $2 \mathrm{C}^{\mathrm{o}}$ acima da temperatura ambiente foi maior para os milhos fortuna e doce $(\mathrm{P}<0,05)$ em relação ao milho reidratado. Porém, quando a inoculação foi realizada a estabilidade do milho doce permaneceu por maior $(\mathrm{P}<0,05)$ período de tempo. Esta variável é considerada uma das mais relevantes, pois segundo Moran et al. (1996) representa o momento no qual ocorre a quebra da 
estabilidade aeróbica das silagens e as mesmas tornam-se impróprias para o fornecimento aos animais de produção.

Segundo Santos et al. (2010) quanto maior for a qualidade das silagens, menor será a estabilidade das mesmas. Deve ser destacado que o milho doce apresentava maior teor de FDN antes da ensilagem (Tabela 1) quando comparado aos demais, o que pode indicar menor valor nutricional (relação carboidratos não fibrosos/FDN menor) e como consequência, apresentar maior estabilidade.

Tabela 2. Estabilidade aeróbica de silagens de grãos úmidos de milho SCS 154 Fortuna EPAGRI $^{\circledR}$, milho doce Tropical Syngenta ${ }^{\circledR}$ e milho reidratado com e sem aplicação de inoculantes e com adição de carboidratases

\begin{tabular}{|c|c|c|c|c|}
\hline \multirow{2}{*}{ Itens } & \multicolumn{4}{|c|}{ Horas para ultrapassar a temperatura de bulbo seco } \\
\hline & $0^{\circ} \mathrm{C}$ & $2^{\circ} \mathrm{C}$ & $5^{\circ} \mathrm{C}$ & $10^{\circ} \mathrm{C}$ \\
\hline & \multicolumn{4}{|c|}{ Tipo de milho } \\
\hline Fortuna $^{1}$ & 40,67 & 43,67 & 47,33 & 50,33 \\
\hline Doce $^{2}$ & 66,33 & 74,67 & 81,67 & 89,00 \\
\hline \multirow[t]{2}{*}{ Reidratado $^{3}$} & 7,33 & 18,50 & 20,92 & 24,00 \\
\hline & \multicolumn{4}{|c|}{ Inoculações } \\
\hline Sem inoculante & 24,73 & 33,73 & 37,64 & 41,82 \\
\hline Com inoculante & 38,27 & 46,09 & 49,91 & 54,64 \\
\hline \multirow[t]{2}{*}{ Inoculante + enzimas } & 44,75 & 51,13 & 56,13 & 60,13 \\
\hline & \multicolumn{4}{|c|}{ Valores de $\mathrm{P}$} \\
\hline Tipos de Milho & $<0,01$ & $<0,01$ & $<0,01$ & $<0,01$ \\
\hline Inoculações & $<0,01$ & $<0,01$ & $<0,01$ & $<0,01$ \\
\hline Inoculações*Tipos milho & $<0,01$ & $<0,01$ & $<0,01$ & $<0,01$ \\
\hline
\end{tabular}

De maneira geral o milho reidratado foi o que apresentou menor $(\mathrm{P}<0,05)$ estabilidade aeróbica. A menor estabilidade pode estar associada a dois fatores, maior presença de fungos e maior quantidade de água disponível. A presença de fungos na massa é um dos fatores que influenciam a estabilidade aeróbica de silagens e o fato dos grãos reidratados terem permanecido por maiores períodos de tempo nas lavouras e ou ficarem armazenados em silos, em conjunto com milhos de outras lavouras, pode resultar em maior concentração de fungos, os quais podem ter acelerado a degradação da massa quando exposta ao ar (PHILLIP \& FELLNER, 1992). O segundo fator, maior quantidade de água disponível, pode ter ocorrido, pois a adição de água pós colheita, pode ter resultado em maior quantidade de água extracelular nas silagens de milho reidratado, quando comparados ao milho colhido no ponto de silagem de grão, desta forma mais disponível para o crescimento microbiano após a abertura e como resultado menor estabilidade aeróbica. 
Tabela 3. Desdobramento das interações da estabilidade aeróbica das silagens de grãos úmidos de milho e milho reidratado de acordo com os tratamentos de inoculação

\begin{tabular}{|c|c|c|c|c|}
\hline \multirow{2}{*}{ Itens } & \multicolumn{4}{|c|}{ Horas para ultrapassar a temperatura do bulbo seco (TBS) } \\
\hline & Fortuna $^{1}$ & Doce $^{2}$ & Reidratado $^{3}$ & Médias \\
\hline Sem inoculante & $38^{\mathrm{Aa}}$ & $42^{\mathrm{Aa}}$ & $6^{\mathrm{Ab}}$ & 29 \\
\hline Com inoculante & $37^{\mathrm{Ab}}$ & $89^{\mathrm{Ca}}$ & $9^{\mathrm{Ac}}$ & 45 \\
\hline Inoculante+enzimas & $47^{\mathrm{Ab}}$ & $68^{\mathrm{Ba}}$ & $7^{\mathrm{Ac}}$ & 41 \\
\hline \multirow[t]{2}{*}{ Médias } & 41 & 66 & 7 & - \\
\hline & \multicolumn{3}{|c|}{ Horas para ultrapassar em $2^{\circ} \mathrm{C}$ a TBS } & Médias \\
\hline Sem inoculante & $42^{\mathrm{Aa}}$ & $53^{\mathrm{Ca}}$ & $17^{\mathrm{Ab}}$ & 37 \\
\hline Com inoculante & $39^{\mathrm{Ab}}$ & $95^{\mathrm{Aa}}$ & $21^{\mathrm{Ac}}$ & 52 \\
\hline Inoculante+enzimas & $50^{\mathrm{Ab}}$ & $76^{\mathrm{Ba}}$ & $16^{\mathrm{Ac}}$ & 47 \\
\hline \multirow[t]{2}{*}{ Médias } & 44 & 75 & 18 & - \\
\hline & \multicolumn{3}{|c|}{ Horas para ultrapassar em $5^{\circ} \mathrm{C}$ a TBS } & Médias \\
\hline Sem inoculante & $46^{\mathrm{Aa}}$ & $59^{\mathrm{Ca}}$ & $20^{\mathrm{Ab}}$ & 42 \\
\hline Com inoculante & $42^{\mathrm{Ab}}$ & $102^{\mathrm{Aa}}$ & $23^{\mathrm{Ac}}$ & 56 \\
\hline Inoculante+enzimas & $54^{\mathrm{Ab}}$ & $84^{\mathrm{Ba}}$ & $18^{\mathrm{Ac}}$ & 52 \\
\hline \multirow[t]{2}{*}{ Médias } & 47 & 82 & 20 & - \\
\hline & \multicolumn{3}{|c|}{ Horas para ultrapassar em $10^{\circ} \mathrm{C}$ a TBS } & Médias \\
\hline Sem inoculante & $49^{\mathrm{Ab}}$ & $67^{\mathrm{Ca}}$ & $22^{\mathrm{Ac}}$ & 46 \\
\hline Com inoculante & $45^{\mathrm{Ab}}$ & $110^{\mathrm{Aa}}$ & $27^{\mathrm{Ac}}$ & 61 \\
\hline Inoculante+enzimas & $57^{\mathrm{Ab}}$ & $90^{\mathrm{Ba}}$ & $20^{\mathrm{Ac}}$ & 56 \\
\hline Médias & 50 & 89 & 23 & - \\
\hline
\end{tabular}

Em relação aos tratamentos de inoculção os mesmos apresentaram diferença apenas no milho doce, para o qual o tratamento com inoculante proporcionou uma maior $(\mathrm{P}<0,05)$ estabilidade. Isso pode ser explicado pelo fato da qualidade das outras silagens serem superiores, de modo que os efeitos dos inoculantes foram insuficientes para inibir a deterioração pós abertura. Porém, na silagem doce, a qual apresentou menor qualidade (Tabela 1), os inoculantes melhoram a estabilidade. As respostas associadas ao tratamento com inoculantes mais enzimas provavelmente são efeitos das enzimas as quais podem ter ocasionado maior exposição de substratos solúveis ao ambiente e ocasionou menor $(\mathrm{P}<0,05)$ estabilidade em relação ao inoculante sem enzimas.
Os valores de $\mathrm{pH}$ as 48, 96, 216, 240 e 296 horas após a abertura (Tabela 4), foram diferentes entre os tipos de milho $(\mathrm{P}<0,05)$, as silagens do milho doce mantiveram os valores de $\mathrm{pH}$ mais baixos até 216 horas após a abertura.

A variação do $\mathrm{pH}$ durante o período de exposição ao ar pode ser um indicativo prático de que a silagem está deteriorada por causa do contato com o ar (KUNG \& KLEINSCHMIT, 2006).

Apesar dos híbridos de milho doce em geral apresentarem teores de açúcares solúveis mais elevados, quando comparados com milho convencional, em torno de 9 a 14\% (SOUZA et al., 2013), a deterioração da massa ocorreu de maneira mais lenta. $\mathrm{O}$ maior teor de FDN do milho doce e, proporcionalmente, menor 
quantidade de nutrientes disponíveis pode ter favorecido sua maior estabilidade no $\mathrm{pH}$ após a abertura. Deve ser destacado que para a colheita do milho doce foi preconizado teor de umidade próximo a $35 \%$, valor superior ao utilizado para a colheita deste híbrido quando utilizado para o consumo humano o que pode ter contribuído para seu maior teor de fibras quando comparado aos demais tipos (Tabela 1).

Tabela 4. Valores de pH após exposição aeróbica das silagens de grãos úmidos de milho SCS 154 Fortuna EPAGRI ${ }^{\circledR}$, milho doce Tropical Syngenta ${ }^{\circledR}$ e milho reidratado com e sem aplicação de inoculantes e com adição de carboidratases

\begin{tabular}{|c|c|c|c|c|c|c|c|c|c|c|}
\hline \multirow{2}{*}{ Itens } & $\mathrm{pH} 0$ & $\mathrm{pH} 24$ & $\mathrm{pH} 48$ & $\mathrm{pH} 72$ & pH96 & pH168 & pH192 & $\mathrm{pH} 216$ & $\mathrm{pH} 240$ & pH296 \\
\hline & & \multicolumn{9}{|c|}{ Tipos de milho } \\
\hline Fortuna $^{1}$ & 3,99 & 3,93 & $5,07^{\mathrm{b}}$ & 6,25 & $7,41^{\mathrm{c}}$ & 7,25 & 7,16 & $7,16^{\mathrm{c}}$ & $7,12^{\mathrm{c}}$ & $7,14^{\mathrm{b}}$ \\
\hline Doce $^{2}$ & 3,94 & 3,94 & $4,01^{\mathrm{a}}$ & 3,94 & $4,28^{\mathrm{a}}$ & 6,37 & 6,67 & $6,09^{\mathrm{a}}$ & $6,70^{\mathrm{b}}$ & $6,47^{\mathrm{a}}$ \\
\hline \multirow[t]{2}{*}{ Reidratado $^{3}$} & 4,02 & 4,30 & $4,86^{\mathrm{b}}$ & 6,47 & $6,66^{\mathrm{b}}$ & 6,54 & 6,54 & $6,55^{\mathrm{b}}$ & $6,46^{\mathrm{a}}$ & $6,46^{\mathrm{a}}$ \\
\hline & & \multicolumn{9}{|c|}{ Inoculações } \\
\hline Sem inoculante & 3,99 & 4,15 & 4,81 & 5,92 & $6,47 \mathrm{a}$ & 6,75 & 6,69 & 6,68 & 6,61 & 6,67 \\
\hline Com inoculante & 4,01 & 3,99 & 4,44 & 5,62 & $6,06 \mathrm{~b}$ & 6,8 & 6,82 & 6,59 & 6,8 & 6,72 \\
\hline \multirow[t]{2}{*}{ Inocul.+enzimas } & 3,96 & 4,14 & 4,81 & 5,63 & $6,12 \mathrm{~b}$ & 6,51 & 6,72 & 6,5 & 6,71 & 6,55 \\
\hline & & \multicolumn{9}{|c|}{ Valores de $\mathrm{P}$} \\
\hline Tipos de milho & NS & 0,15 & $<0,01$ & $<0,01$ & $<0,01$ & $<0,01$ & $<0,01$ & $<0,01$ & $<0,01$ & $<0,01$ \\
\hline Inoculações & NS & NS & 0,91 & 0,46 & $<0,01$ & 0,256 & 0,09 & 0,31 & 0,07 & 0,46 \\
\hline Inoculação*milho & NS & NS & 0,38 & 0,02 & 0,70 & $<0,01$ & 0,03 & 0,15 & 0,27 & 0,61 \\
\hline
\end{tabular}

*Valores seguidos de letras minúsculas na coluna diferem pelo teste de Tukey $(\mathrm{P}<0,05)$.

${ }^{1}$ Silagem de grãos úmidos de milho SCS 154 Fortuna Epagri ${ }^{\circledR} ;{ }^{2}$ Silagem de grãos úmidos de milho Tropical Syngenta ${ }^{\circledR} ;{ }^{3}$ Silagem de milho reidratado.

Os valores de $\mathrm{pH}$ após 72, 168 e 192 horas da abertura dos silos apresentaram interação $(\mathrm{P}<0,05)$ entre os tratamentos de inoculação e tipos de milho. $\mathrm{O}$ desdobramento das interações (Tabela 5) indicaram que as silagens de milho doce apresentaram menores valores de $\mathrm{pH} 72$ quando comparados ao reidratado no tratamento sem inoculante e com inoculação mais enzimas $(\mathrm{P}<0,05) \quad \mathrm{e}$ menor $\mathrm{pH}$ que a silagem de milho fortuna no tratamento com inoculação.

A leitura de $\mathrm{pH}$ na hora 168 indicou que o milho reidratado apresentou melhores resultados de $\mathrm{pH}$ quando houve inoculação mais enzimas. Para o pH 192 horas o milho reidratado e o doce apresentaram menor $\mathrm{pH}$ que o milho fortuna nos tratamentos com e sem inoculação e o milho reidratado apresentou valores de $\mathrm{pH}$ inferiores aos demais tipos de milho no tratamento inoculante mais enzimas. As diferenças observadas nesta etapa podem estar relacionadas com as diferentes composições de cada tipo de milho (Tabela 1).

Ao mensurar os valores de $\mathrm{pH}$ até 72 horas de exposição ao ar para a variedade de milho doce foi verificado que a massa ensilada apresentava valor de 3,94 
unidades de $\mathrm{pH}$. De acordo com Kung \& Kleinschmit (2006), valores entre 3,8 a 4,2 unidades de $\mathrm{pH}$ na abertura, podem ser considerados indicativos de uma boa conservação da massa ensilada. No caso do milho doce, como mencionado anteriormente, pode estar associado à menor disponibilidade de nutrientes solúveis.

Tabela 5. Desdobramento das interações dos valores de pH após a exposição aeróbica das silagens de grãos úmidos de milho e milho reidratado com e sem aplicação de inoculantes e com adição de carboidratases

\begin{tabular}{|c|c|c|c|c|}
\hline \multicolumn{5}{|c|}{$\mathrm{pH} 72$ horas } \\
\hline Itens & Fortuna $^{1}$ & Doce $^{2}$ & Reidratado $^{3}$ & Médias \\
\hline Sem inoculante & $6,55^{\mathrm{ab}}$ & $3,95^{\mathrm{b}}$ & $6,72^{\mathrm{a}}$ & 5,74 \\
\hline Com inoculante & $6,74^{\mathrm{a}}$ & $3,94^{\mathrm{b}}$ & $5,95^{\mathrm{ab}}$ & 5,54 \\
\hline Inoculante+enzimas & $5,46^{\mathrm{ab}}$ & $3,93^{b}$ & $6,75^{\mathrm{a}}$ & 5,38 \\
\hline Médias & 6,25 & 3,94 & 6,47 & - \\
\hline \multicolumn{4}{|c|}{$\mathrm{pH} 168$ horas } & Médias \\
\hline Sem inoculante & $7,28^{\mathrm{Aa}}$ & $6,59^{\mathrm{Ab}}$ & $6,53^{\mathrm{Ab}}$ & 6,80 \\
\hline Com inoculante & $7,32^{\mathrm{Aa}}$ & $6,03^{\mathrm{Ab}}$ & $6,94^{\mathrm{Aa}}$ & 6,76 \\
\hline Inoculante+enzimas & $7,15^{\mathrm{Aa}}$ & $6,49^{\mathrm{Ab}}$ & $6,15^{\mathrm{Bb}}$ & 6,60 \\
\hline Médias & 7,25 & 6,37 & 6,54 & - \\
\hline \multicolumn{4}{|c|}{ pH 192 horas } & Médias \\
\hline Sem inoculante & $7,14^{\mathrm{a}}$ & $6,68^{b}$ & $6,42^{b}$ & 6,75 \\
\hline Com inoculante & $7,24^{\mathrm{a}}$ & $6,48^{\mathrm{b}}$ & $6,78^{\mathrm{b}}$ & 6,83 \\
\hline Inoculante + enzimas & $7,10^{\mathrm{a}}$ & $6,87^{\mathrm{a}}$ & $6,41^{\mathrm{b}}$ & 6,79 \\
\hline Médias & 7,16 & 6,67 & 6,54 & - \\
\hline
\end{tabular}

O modelo matemático que minimizou os erros entre os valores estimados e observados de $\mathrm{pH}$, para os tipos de inoculação, ao longo da exposição ao ar (Figura 1), foi o proposto por Richard (1959). O referido modelo foi proposto inicialmente para descrever o crescimento de plantas (LIMA \& SILVA, 2003). Provavelmente, o crescimento microbiano após a abertura dos silos e a consequente alteração do $\mathrm{pH}$, estão relacionadas ao metabolismo biológico e seguem a Lei de rendimentos decrescentes, com o princípio de que o crescimento é uniformemente acelerado, alcança o ponto de inflexão e desacelera até chegar a zero (MACHADO et al., 2014). A partir deste preceito a curva gerada pelo modelo de Richards (1959) possui uma fase de crescimento exponencial, um ponto de inflexão, e uma fase de crescimento auto inibido (THORNLEY \& FRANCE, 2007). 


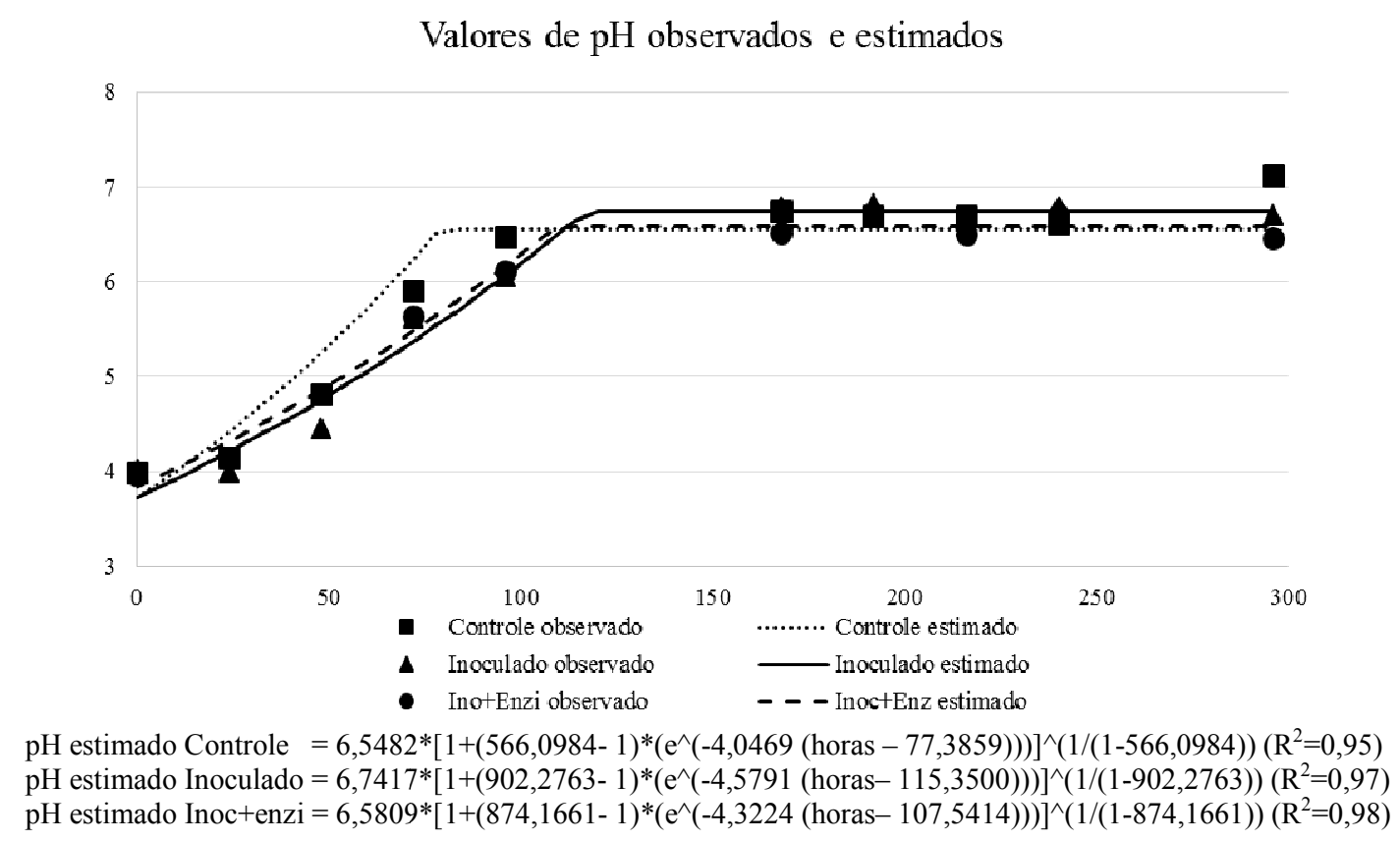

Figura 1. Ajuste das curvas de $\mathrm{pH}$ após abertura dos silos em relação aos tratamentos sem inoculante; com inoculante bacteriano; e com inoculante mais enzimas, por meio do modelo de Richard (1959)

Balieiro Neto et al. (2009), verificaram acréscimo nos valores de $\mathrm{pH}$ em silagens de cana-de-açúcar com o avanço do tempo de exposição ao oxigênio (aproximadamente 8,3 após 7 dias de avaliação), valores superiores aos obtidos neste estudo, provavelmente resultados das diferentes características das silagens estudadas pelo autor $\mathrm{e}$ as do presente trabalho.

Para as silagens de milho reidratado o modelo proposto por Richard (1959), foi o que minimizou o quadrado dos erros, semelhante aos resultados obtidos para as inoculações.

Entretanto, para o milho fortuna e o milho doce foi o modelo proposto por Morgan et al. (1975). Esta equação foi desenvolvida inicialmente para descrever o crescimento de animais superiores de acordo com o nível nutricional, com limites assintóticos e taxa de crescimento exponencial.

A diferença obtida para o modelo matemático utilizado para os as silagens com os milhos Fortuna e Doce, com melhor ajuste com o modelo de Morgan et al. (1975), podem estar associados à microbiota epífita dos grãos, visto que estas duas variedades foram plantadas no mesmo local, período e passaram pelos mesmos manejos de solo, adubação, colheita e processamento, o que resultou em perfil de microbiota diferente do milho reidratado.

A microbiota epífita dos grãos, segundo Ítavo et al. (2006), pode ser suficiente para garantir adequada fermentação, o que reforça a hipótese de que a microbiota natural pode ter contribuído para o melhor ajuste com a equação de Morgan et al. (1975), para as silagens com os milhos Fortuna e Doce. 


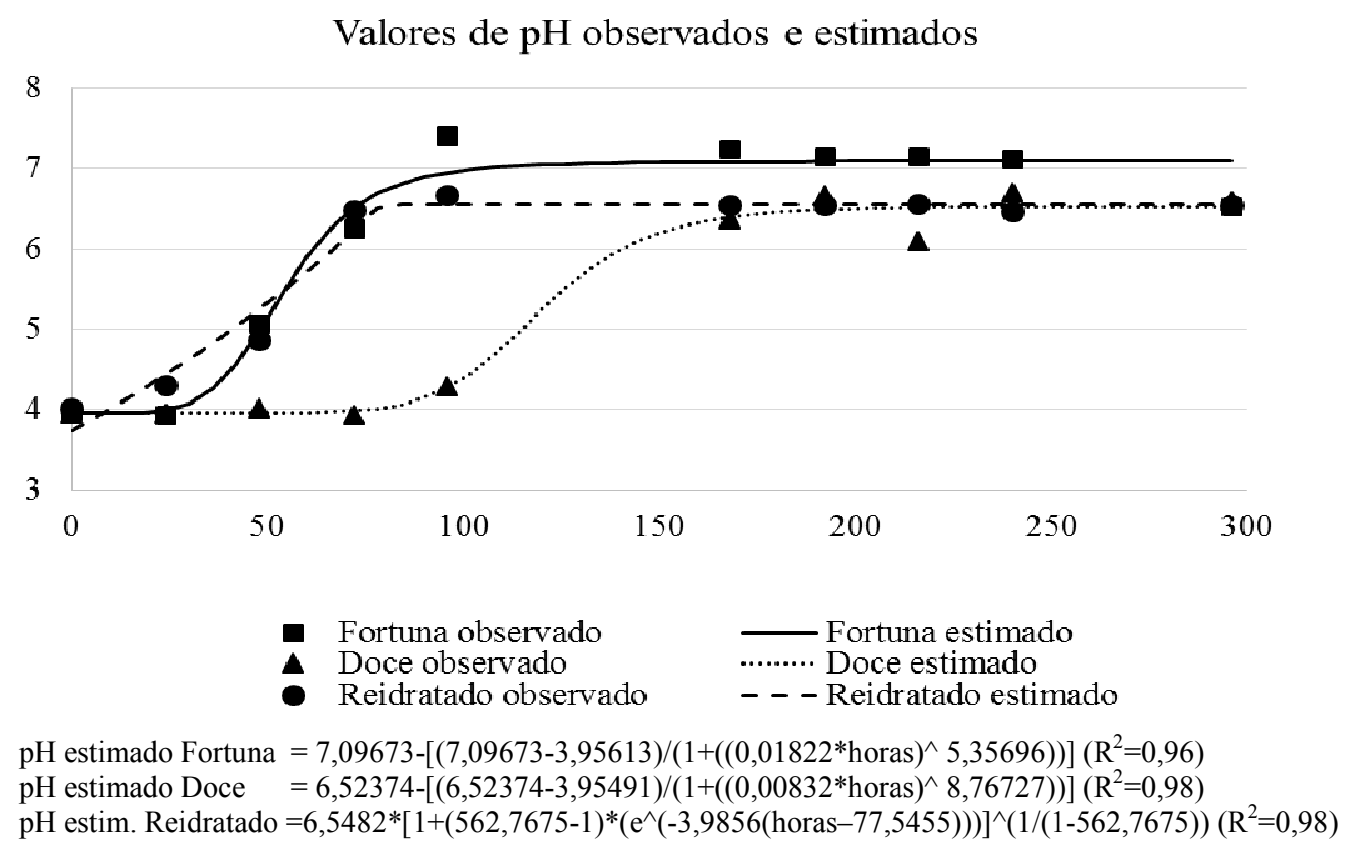

Figura 2. Ajuste das curvas de $\mathrm{pH}$ após abertura dos silos em relação aos tipos de milho por meio do modelo de Morgan et al. (1975) ou Richard (1959)

Houve interação $(\mathrm{P}<0,05)$ entre os tratamentos de inoculação e tipos de milho para a estabilidade aeróbica e para pH após 72, 168 e 192 horas após a abertura dos silos. As silagens de milho doce inoculadas apresentaram a menor taxa de perda na estabilidade aeróbica quando comparadas com as demais silagens. Para o $\mathrm{pH} 48$ horas as silagens de milho doce apresentaram menores valores quando comparados ao demais tipos de milho independente do tratamento $\quad(\mathrm{P}<0,05) . \quad \mathrm{O}$ tratamento inoculação mais enzimas para a silagem de milho reidratado reduziu o $\mathrm{pH}$ 168. A equação de Richard (1959) foi a que melhor estimou os valores de $\mathrm{pH}$ para os tipos de inoculação e para a silagem de milho reidratado. Para as silagem de milho fortuna e doce o modelo proposto por Morgan et al. (1975) foi o que melhor ajustou os dados.

\section{REFERÊNCIAS}

BALIEIRO NETO, G.; SIQUEIRA, G.R.; NOGUEIRA, J.R.; REIS, R.A.; ROTH, A.P.T.P.; ROTH, M.T.P. Perdas fermentativas e estabilidade aeróbia de silagens de cana de-açúcar aditivadas com cal virgem. Revista Brasileira de Saúde e Produção Animal [online], v.10, n.1, p.24-33, 2009.

BERNARDES, T.F.; NUSSIO, L.G.; AMARAL, R.C. Top spoilage losses in maize silage sealed with plastic films with different permeabilities to oxygen. Grass and Forage Science, v.67, n.1, p.34-42, 2012. 
DOLCI, P.; TABOCCO, E.; COCOLIN, L.; BORREANI, G. Microbial dynamics during aerobic exposure of corn silage stored under oxygen barrier or polyethylene films. Applied and Environmental Microbiology, v.77, n.21, p.7499-7507, 2011.

GIMENES, A.L.G.; MIZUBUTI, I.Y.; MOREIRA, F.B.; PEREIRA, E.S.; RIBEIRO, E.L.A.; MORI, R.M.

Composição química e estabilidade aeróbia em silagem de milho preparadas com inoculantes bacteriano e/ou enzimático. Acta Scientiarum, v.28, n.2, p.153-158, 2006.

GOMPERTZ, B. On the nature of the function expressive of the low of human mortality, and a new mode of determining the value of live contengencies.

Philosophical Transactions of Royal Society, v.182, p.513-585, 1825.

HAVERKAMP, R.; PARLANGE, J.Y. Predicting the water-retention curve from particle-size distribution: I. sandy soils without organic matter. Soil Science Society of America Journal, v.142, n.6, p.325-339, 1986.

HOEDTKE, S.; ZEYNER, A.

Comparative evaluation of laboratoryscale silages using standard glass jar silages or vacuum-packed model silages. Journal of the Science of Food and Agriculture, v.91, n.5, p.841-849, 2011.

ÍTAVO, C.C.B.F.; MORAES, M.G.; ÍTAVO, L.C.V.; SOUZA, A.R.D.L.; DAVY, F.C.A.; ALBERTINI, T.Z.; COSTA, C.; LEMPP, B.; JOBIM, C.C. Padrão de fermentação e composição química de silagens de grãos úmidos de milho e sorgo submetidas ou não a inoculação microbiana. Revista

Brasileira de Zootecnia, v.35, n.3, p.655-664, 2006.

JOBIM, C. C.; NUSSIO, L. G.; REIS, R. A.; SCHIMIDT, P. Avanços metodológicos na avaliação da qualidade da forragem conservada. Revista

Brasileira de Zootecnia, v.36, suplemento especial, p.101-119, 2007.

KUNG, J.R.L.; KLEINSCHMIT, D.H. A meta-analysis of the effects of lactobacillus buchneri on the fermentation and aerobic stability of corn and grass and small-grain silages.

Journal of Dairy Science, v.89, n.10, p.4005-4013, 2006.

KUNG, J.R.L.; TAYLOR, C.C.; LYNCH, M.P.; NEYLON, J.M. The effects of treating alfalfa with Lactobacillus buchneri 40788 on silage fermentation, aerobic stability, and nutritive value for lactating dairy cows. Journal of Dairy Science, v.86, n.1, p.336-343, 2003.

LIMA, J.E.F.W.; SILVA, E.M. Boletim de pesquisa e desenvolvimento. Teste e comparação de modelos matemáticos para o traçado de curvas granulométricas. Embrapa 2003.

Disponível em:

$<$ http://www.infoteca.cnptia.embrapa.br/ handle/doc/569214>. Acesso em: 18 out. 2013.

MACHADO, S.A.; ZAMIN, N.T.; NASCIMENTO, R.G.M.; SANTOS, A.A.P. Efeito das variáveis climáticas no crescimento mensal de espécies florestais em fase juvenil. Revista Floresta e Ambiente, v.21, n.2, p.170-81, 2014. 
MAKKINK, C.A.; NEGULESCUS'S, G.P.; GUIXIN, Q.; VERSTEGEN, M.W.A. Effect of dietary protein source on feed intake, growth, pancreatic enzyme activities and jejunal morphology in newly-weaned piglets. British Journal of Nutrition, v.72, n.3, p.353-368, 1994.

MENDES, C.Q.; SUSI, I.; NUSSIO, L.G.; PIRES, A.V.; RODRIGUES, G.H.; URANO, F.S. Efeito do Lactobacillus buchneri na fermentação, estabilidade aeróbia e no valor nutritivo de silagem de cana-de-açúcar. Revista Brasileira de Zootecnia, v.37, n.12, p.2191-2198, 2008.

MORAN, J.P.; WEINBERG, Z.G.; ASHBELL, G.; HEN, Y.; OWEN, T.R. A comparison of two methods for the evaluation of the aerobic stability of whole crop wheat silage. In:

INTERNATIONAL SILAGE CONFERENCE, 11, 1996, Aberystwyth. Proceedings... Aberystwyth: University of Wales Aberystwyth, 1996. p. 162-163.

MORGAN, P.H.; MERCER, L.P.; FLODIN, N.W. General model for nutritional responses of higher organisms. Proceedings of the National Academy of Sciences, v.72, n.11, p.4327-4331, 1975.

NEUMANN, M.; MÜHLBACH, P.R.F.; NÖRNBERG, J.L.; OST, P.R.; RESTLE, J.; SANDINI, I.E.; ROM, M.A.

Características da fermentação da silagem obtida em diferentes tipos de silos sob efeito do tamanho de partícula e da altura de colheita das plantas de milho. Ciência Rural, v.37, n.3, p.847-854, 2007.
PHILLIP, L.E.; FELLNER, V. Effects of bacterial inoculation of high-moisture ear corn on its aerobic stability, digestion, and utilization for growth by beef steers. Journal of Animal Science, v.70, n.10, p.3178-3187, 1992.

RABELO, C.H.S.; REZENDE, A.V.; NOGUEIRA, D.A.; RABELO, F. H.S.; SENEDESE, S.S.; VIEIRA, P.F.; BARBOSA, L.Á.; CARVALHO, A. Perdas fermentativas e estabilidade aeróbia de silagens de milho inoculadas com bactérias ácido-láticas em diferentes estádios de maturidade. Revista

Brasileira de Saúde Produção Animal [online], v.13, n.3, p.656-668, 2012.

RICHARDS, F.J.A. Flexible growth function for empirical use. Journal of Experimental Botany, v.10, n.2, p.290300, 1959.

RODRIGUES, P.H.M.; PEDROSO, S.B.D.G.; MELOTTI, L.; ANDRADE, S.J.T.D.; LIMA, F.R.D. Composição bromatológica e perfil fermentativo da silagem de capim-elefante obtida em diferentes tipos de silos experimentais e no silo tipo trincheira. Revista Brasileira de Zootecnia, v.31, n.6, p.2386-2392, 2002 .

SANTOS, M.V.F.; GÓMEZ CASTRO, A.G.; PEREA, J.M.; GARCIA, A.; GUIM, A.; PEREZ HERMÁNDEZ, M. Fatores que afetam o valor nutritivo das silagens de forrageiras tropicais.

Arquivos de Zootecnia, v.59, (R), p.2543, 2010.

SILVA, D.J.; QUEIROZ, A.C Análise de alimentos: métodos químicos e biológicos. 3ed. Viçosa, Universidade Federal de Viçosa, 2002. 235p. 
SILVA, M.A.A.; FURLAN, A.C.; MOREIRA, I.; PAIANO, D.; JOBIM, C.C.; BARCELLOS, L.C.G. Avaliação nutricional do milho com maior teor de óleo, nas formas de grãos secos e silagens, para suínos nas fases de crescimento e terminação. Revista Brasileira de Zootecnia, v.35, n.3, p.830-839, 2006.

SOUZA, R.S.; VIDIGAL FILHO, P.S.; SCAPIM, C.A.; MARQUES, O.J.; QUEIROZ, D.C.; OKUMURA, R.S.; RECHE, D.L.; CORTINOVE, V.B.

Produtividade e qualidade do milho doce em diferentes populações de plantas.

Semina: Ciências Agrárias, v.34, n.3, p.995-1010, 2013.

THORNLEY, J.H.M.E.; FRANCE, J.

Mathematical models in agriculture: quantitative methods for the plant, animal and ecological sciences. 2nd ed. Oxon, UK: CABI, 2007. 906 p.

ZÁRATE, N.A.H.; VIEIRA, M. do C. Produção do milho doce cv. Super doce em sucessão ao plantio de diferentes cultivares de inhame e adição de cama de frango. Horticultura Brasileira, v.21, n.1, p.05-09, 2003.

Data de recebimento: 08/10/2014

Data de aprovação: 29/06/2016 